\title{
RECONFIGURACIÓN METABÓLICA Y ACUMULACIÓN POR DESPOSESIÓN: LA INDUSTRIA MINERA DEL COBRE Y EL CASO DE LA MINERA LOS PELAMBRES EN LA CUENCA DEL RÍO CHOAPA
}

\author{
METABOLIC RECONFIGURATION AND ACCUMULATION BY DISPOSAL: \\ THE MINERAL INDUSTRY OF COPPER AND THE CASE OF MINERA LOS \\ PELAMBRES IN THE BASIN OF THE CHOAPA RIVER
}

\author{
Alejandro Esteban Carrasco Luna*
}

\begin{abstract}
Actualmente asistimos a una creciente conflictividad social estructurada en torno a la radicación de megaproyectos de carácter extractivista. La literatura referente a los conflictos socioambientales se ha enfocado mayoritariamente en las consecuencias ambientales, dejando de lado los factores que han permitido la materialización de los diversos proyectos. El presente artículo analiza la instalación del complejo minero Los Pelambres desde una perspectiva histórico-ecológica. Abordado como una expresión concreta de la producción de la naturaleza capitalista y de las dinámicas de acumulación por desposesión, la instalación del complejo minero Los Pelambres significó la reconfiguración metabólica de la cuenca del Choapa, determinando a su vez la reconfiguración de las energías vitales que en ella habitan
\end{abstract}

Palabras claves: Reconfiguración metabólica, acumulación por desposesión, Minera Los Pelambres.

Currently we are witnessing an increasing social unrest structured around the establishment of mega projects with extractivist features. The literature on socio-environmental conflicts has focused primarily on environmental consequences, leaving aside the factors that have allowed the materialization of diverse projects. This paper analyzes the installation of the mining complex Los Pelambres from an ecological-historical perspective. Approached as a concrete expression of the production of capitalist nature and the dynamics of accumulation by dispossesion, the establishment of the mining complex Los Pelambres meant the metabolic reconfiguration of the Choapa basin determining, in turn, the reflux of vital energies that inhabit it.

Key words: Metabolic reconfiguration, accumulation by dispossesion, mining complex Los Pelambres.

\section{Introducción}

En el contexto de las políticas neoliberales y sus respectivas reformas institucionales funcionales al nuevo proceso de acumulación capitalista, América Latina se ha consolidado como centro privilegiado para la radicación de grandes capitales ligados a la vocación extractivista en general, y a la extracción minera en particular. Por consiguiente, desde la última década del siglo pasado, marcada por el auge de la Gran Minería, asistimos al estallido de una intensa y creciente conflictividad social estructurada en torno a la radicación de megaproyectos de apropiación y explotación de la naturaleza. Uno de los megaproyectos impulsado por las dinámicas anteriormente descritas es el Complejo minero Los Pelambres (CMLP), ubicado en la comuna de Salamanca, IV Región de Coquimbo, Chile.
En las siguientes líneas se abordará la instalación del CMLP desde una perspectiva histórico-ecológica. Como una expresión concreta de la producción de la naturaleza capitalista y de las dinámicas de acumulación por desposesión. Además, lejos de concebirlo como un conflicto aislado, se analiza dentro de un proceso mucho más complejo y estructural: el desarrollo de la industria minera y el capitalismo a nivel nacional y mundial. En concreto, nos interesa comprender ¿cuáles fueron los factores históricoecológicos que permitieron la materialización del Complejo Minero Los Pelambres en la cuenca del río Choapa?

Nuestra metodología giró en torno al análisis de fuentes bibliográficas que nos permitan exponer el marco general dentro del cual se desplegó nuestro objeto de estudio. A lo anterior se agregará la prospección y análisis de fuentes estadísticas y de

\footnotetext{
* Universidad Academia de Humanismo Cristiano, Santiago, Chile. Correo electrónico: alegeohist@ gmail.com
} 
carácter legal. En este sentido podemos destacar las evaluaciones de impacto ambiental y las resoluciones de la Corporación Regional de Medioambiente (COREMA), Así como también análisis estadísticos acerca de la producción, exportación y caracterización de la industria minera, provenientes de la Corporación Chilena del Cobre (COCHILCO) y de la Sociedad Nacional de Minería (SONAMI).

\section{Conflictos mineros. Una perspectiva ecológica o ambiental}

El abordaje de la industria minera desde una perspectiva ecológica o ambiental es reciente y, en concordancia con la propia historia ambiental y las preocupaciones por el medio ambiente, responde a las discusiones desarrolladas respecto de la relación entre la naturaleza y el ser humano desde la segunda mitad del siglo XX. En consecuencia, esta perspectiva se constituye como uno de los enfoques menos trabajados, y a su vez de mayor potencialidad futura.

En primera instancia podemos identificar una serie de autores que abordan la industria minera en relación con los procesos político-sociales y la institucionalidad vigente. Pionero es el trabajo de Pablo Camus y Ernst R. Hajek (1998), quienes desarrollaron un análisis de la historia de Chile desde 1964 hasta 1994 desde una perspectiva ambiental. La explicación la construyen en torno a la descripción de cuatro sectores en donde se desenvuelve la economía chilena: sector forestal, pesquero, minero y urbano. Mauricio Folchi (2003), por su parte, analiza la relación entre la industria minera y la institucionalidad, centrándose en tres aspectos: primero, el nuevo marco jurídico-institucional que promociono; en segundo lugar, el aumento de la producción (expansión de yacimientos tanto de propiedad pública como privada); y finalmente, el nacimiento de una política ambiental impulsada por los gobiernos democráticos en busca de la regulación y fiscalización de la actividad minera.

Otro grupo de autores que podemos identificar tienen relación con el abordaje de conflictos específicos desatados por la industria minera y sus respectivos impactos, tanto ambientales como sociales. Nancy Yáñez Fuenzalida y Raúl Molina (2008) articulan una perspectiva de largo plazo de la industria minera en la zona andina, haciendo referencia a la precarización y usurpación que han vivido los pueblos indígenas del norte de Chile a raíz de la instalación de complejos mineros. Por otra parte, la obra de Ángela Vergara (2011) es un claro ejemplo en cuanto a la constatación, mediante un estudio de caso, de la contaminación y degradación del medio ambiente y las comunidades por parte de la industria minera. Tomando como ejemplos los complejos mineros de Potrerillos y El Salvador, explica el proceso productivo y del rol de los recursos hídricos en la industria minera, poniendo énfasis en la construcción de los relaves tóxicos y su derrame sobre el río Salado, y dando cuenta de los efectos contaminantes y de las dinámicas contestatarias que desarrollaron las comunidades afectadas. Más reciente es el artículo de Camilo Cepeda Francese (2016), quien analiza las luchas sociales desplegadas en el Norte de Chile, más específicamente en Calama, en torno al extractivismo minero. Lo interesante de este artículo es que señala que la demanda principal de los movimientos es una mejor redistribución de la renta minera, y no necesariamente un discurso antiminero. Las dos últimas obras se acercan de manera importante a la propuesta investigativa del presente trabajo.

Si bien en gran parte provenientes desde otras disciplinas como la geografía, antropología, y en menor medida desde la historiografía, los conflictos desatados por la industria minera han sido abordados principalmente desde las consecuencias o impactos ambientales y sociales que la actividad minera tiene en una localidad específica, dejando en segundo plano o invisibilizando las causas estructurales que han originado e impulsado dichas dinámicas contaminantes. De este modo, creemos que la instalación del Complejo Minero Los Pelambres no se puede analizar solamente desde una perspectiva que ponga en el centro de atención las consecuencias ambientales, o por otro lado solamente el análisis social del conflicto. La materialización del Complejo Minero Los Pelambres responde a una conjugación de elementos. A saber, el desarrollo del capitalismo y su particular forma de producir la naturaleza.

\section{La instalación del Complejo Minero Los Pelambres como reconfiguración metabólica de la cuenca del río Choapa}

$\mathrm{Al}$ igual que Marx (1844), partimos de la premisa que comprende que la naturaleza es el cuerpo inorgánico del hombre, y ambos permanecen en un continuo intercambio para no morir. En este sentido, partir de la materialidad corporal de la existencia humana, el ser humano viviente, implica en primera 
instancia reconocer que las relaciones humanas y sociales acontecen siempre dentro del mundo de la materia viva, y por otro lado, que los seres humanos provenimos del proceso de despliegue y lo complejo de la naturaleza, y que fisiológicamente dependemos de ella (Machado 2016:212).

En términos históricos, esta reorientación presenta la naturaleza más que como recurso o entidad exterior a las relaciones sociales, como matriz para el análisis histórico. Siguiendo a Moore (2014:92), "la naturaleza, en cambio, se convierte en la matriz dentro de la cual se despliega la actividad humana, y el campo sobre el que la agencia histórica opera". Para dar cuenta de este giro epistemológico, y de la reciprocidad dialéctica entre el ser humano y la naturaleza, nos apoyaremos en lo que Marx acuñó como metabolismo social, el que sería:

la condición y el proceso ecológico-político fundamental a través del cual los individuos y las sociedades humanas procuran su propia subsistencia; vale decir, producen en general, su vida, su modo de vida. Tal proceso consiste concretamente en los flujos de intercambios energético-materiales que vinculan a los cuerpos humanos vivientes con la tierra como medio de vida, y que tienen en el alimento y en el trabajo sus dos vectores ecobiopolíticos claves (Machado 2016:215).

Lo planteado hasta ahora se constituye como discurso crítico al dualismo sociedad-naturaleza o capitalismo-naturaleza, propugnado por las ciencias modernas y el cartesianismo. Por tanto, nuestra investigación parte de una premisa muy concreta: no existe el ser humano por fuera o por arriba de la naturaleza, y, por esta razón, no existen las relaciones sociales por fuera de la naturaleza. Son parte de ella, productoras de una forma específica de naturaleza, y producidas a la vez por ella. Bajo esta premisa, el desarrollo del capitalismo no tiene consecuencias sobre la naturaleza, más bien, como Moore señala (2013:12), la acumulación del capital es la transformación de la tierra. Dicho de otra forma, el capitalismo requiere apropiación de la naturaleza humana y extrahumana para reproducirse (O'Connor 2001:200).

Por consiguiente, la instalación del Complejo Minero Los Pelambres se constituye como expresión concreta de una forma de producir la naturaleza humana y extrahumana-signada por la necesidad de acumulación de capital-en donde la reconfiguración de la cuenca del Choapa representa -y determinan-, a su vez, la reconfiguración de las energías vitales que en ella habitan (comunidades, flora, fauna, sistemas hidrológicos, glaciares, etc.). No obstante, que la acumulación de capital sea la transformación de la tierra, significa que las implicancias ambientales de la instalación del Complejo Minero Los Pelambres en la cuenca del Choapa son solo una dimensión de la producción de la naturaleza/medio ambiente. A esta debemos sumarle la compleja red de factores histórico-ecológicos que permitieron su materialización, por ejemplo, la profunda reestructuración capitalista de la década de 1970, y, por consiguiente, las reformas que profundizaron la vocación minera.

\section{Reestructuración capitalista y acumulación por desposesión}

La crisis de sobreacumulación desarrollada en la década de 1970 obligó al capitalismo a buscar o profundizar nuevas formas de acumulación que le permitieran su propia reproducción. El capitalismo necesitó transformarse para sobrevivir. La forma adquirida hegemónicamente por el capitalismo a nivel mundial fueron las políticas económicas provenientes de la doctrina neoliberal. Una doctrina caracterizada por "derechos de propiedad privada, fuertes mercados libres y libertad de comercio" (Harvey 2007:6).

La importancia en torno a la discusión de los procesos de explotación y mercantilización de los bienes comunes en la nueva fase neoliberal derivó en el creciente uso del término extractivismo o modelo extractivo exportador. En este sentido, podemos definir el extractivismo como una modalidad de acumulación, que desde hace medio siglo se extiende con diversos grados de intensidad en América Latina (Composto y Navarro 2012:8). Siguiendo lo planteado por Gudynas (2015:13), el extractivismo consiste primeramente en un modelo productivo que se basa en la sobreexplotación de bienes naturales, que sin ningún procesamiento o con alguno poco significativo, son apropiados privadamente y vendidos en el mercado mundial. En segundo lugar, cuando se habla se sobreexplotación se hace referencia a una tasa de extracción que no respeta los tiempos biológicos, químicos y geológicos de reposición natural. Y, por último, el extractivismo se remite 
tradicionalmente a las actividades económicas cuyo núcleo dinámico reside en la apropiación de bienes naturales no renovables, como los hidrocarburos y minerales. Para el campo de la teoría crítica, el término "extractivismo" o "modelo extractivista" ha facilitado la identificación de una unidad socioeconómica que se caracteriza por las lógicas de la devastación ambiental y la apropiación de los bienes naturales. No obstante, como señala Seoane (2012:6), su carácter descriptivo puede dificultar la comprensión de las relaciones que el modelo extractivista guarda con la totalidad social; su papel en la configuración de los bloques en el poder y las relaciones de clase, así como sobre el carácter capitalista de la formación social. En consecuencia, y con el afán de complementar sus alcances y límites, proponemos dialogar con la categoría que David Harvey $(2003,2004)$ acuñó como "Acumulación por desposesión". La desposesión se presenta como el ejercicio mediante el cual se ofreció una solución a la crisis y que, a nuestro parecer, su uso se fundamenta en al menos tres elementos convergentes.

En primera instancia, permite dar cuenta del renovado y amplificado proceso de mercantilización o privatización que caracteriza a la fase capitalista neoliberal. En este sentido, ya no solo nos referimos a la mercantilización de bienes naturales (minerales, agua, bosques), sino también a bienes sociales (cultura, educación, salud, identidad, derechos laborales, previsión, etc.). Tanto la privatización como la mercantilización se han encargado de destrabarle al capital nuevos campos para el ejercicio de la acumulación. El segundo elemento a destacar es el rol del Estado en los procesos de apropiación de bienes naturales y destrucción de ecosistemas, que lejos de tener una ausencia de la actividad económica, son un actor activo en la promoción y consolidación de los elementos institucionales que el capital necesita para el ejercicio de la acumulación (Harvey 2004:145). En tercer lugar, permite vincular la noción de "extractivismo" con la de "violencia", la que se expresa en el sistemático uso de la coacción, legitimada por el Estado, para garantizar el ejercicio del despojo (Seoane 2013:28, 36). En efecto, los procesos de apropiación de los bienes naturales, la sobreexplotación de los ecosistemas o la contaminación, implican necesariamente el uso de la violencia, el fraude, la corrupción y el autoritarismo. El ejercicio de la violencia no es irracional ni una mera casualidad, sino más bien un mecanismo inherente al proceso de acumulación capitalista.

En términos históricos, el golpe de Estado perpetuado el 11 de septiembre de 1973 marca el momento decisivo en cuanto a la promoción e intensificación de las dinámicas anteriormente descritas. Se constituye como expresión de una necesidad para el proceso de acumulación capitalista, por tanto, no se puede comprender como un acontecimiento aislado de los procesos globales. Como señala Gárate (2012:261), la privatización de las empresas del Estado se constituyó como factor clave para comprender el nuevo paradigma neoliberal puesto en práctica. Así es como, inmediatamente posterior al golpe de Estado, aproximadamente 300 empresas que estaban en plena transferencia hacia el Estado fueron devueltas a sus antiguos propietarios. Si bien la crisis de 1982 generó, como en la totalidad de las políticas económicas, un periodo de pragmatismo, una vez superada, se reinició el proceso de privatizaciones. En esta nueva fase se incluyeron empresas pertenecientes a la CORFO, así como CTC y ENTEL, ENDESA, CAP y LAN-Chile. No obstante, permanecieron en el Estado CODELCO, ENAP y el Banco del Estado, consideradas estratégicas para los militares.

La dictadura también llevó a cabo varias reformas sociales (Gárate 2012:262), caracterizadas, en consecuencia, con lo señalado anteriormente, por las lógicas privatizadora y mercantilizadora. Así es como tanto las reformas a la salud, educación, sistema de pensiones, y a la legislación laboral, pasaron de ser concebidas como derechos sociales y resguardadas por el Estado, a ser consideradas un servicio, un producto; una mercancía. Dichas reformas son fundamentales, ya que, por ejemplo, gracias a la reforma previsional, los capitales tanto nacionales como transnacionales pudieron sortear la falta de recursos necesarios para la compra de los activos públicos.

\section{Minera Los Pelambres, correlato histórico de la industria minera}

Históricamente Chile se constituyó como un país exportador de minerales a gran escala. En este sentido, la vocación Minera ha cumplido un factor clave y estratégico en el proceso de modernización económica e inserción del país en el mercado mundial (Ortega y Pinto 1990). Para la década de 1860 la expansión de la minería del cobre terminó 
por abastecer el $44 \%$ del consumo mundial (Pinto y Salazar 2002:94).

Dos son los factores que, al comenzar el siglo XX, permitieron la consolidación de la industria del cobre. Desde 1910, con el cobre como protagonista y los subproductos oro, plata y molibdenita, se inicia el periodo de cobre porfídico (Pederson 1996), el que, gracias al desarrollo de nuevas técnicas como la flotación y lixiviación, han permitido la explotación de nuevos depósitos que no eran rentables con las técnicas anteriormente desarrolladas. El CMLP, aunque ya finalizando el siglo XX, es parte de los nuevos depósitos que fueron posible explotar.

El segundo factor radica en el desplazamiento sustantivo de los productores nacionales a costa de la irrupción del capital norteamericano (Pinto y Salazar 2002:119). Provistos de los capitales y la tecnología necesaria para aprovechar los yacimientos de cobre porfírico, grandes consorcios como Guggenheim, Kennecott y Anaconda pusieron en marcha los complejos mineros de El Teniente, Potrerillos y Chuquicamata, de estos dependería gran parte de la economía nacional del siglo XX. Solo entre 1906 y 1929 la producción chilena de cobre subió de 26.000 a 320.000 toneladas métricas anuales, con lo que su aporte a la oferta mundial pasó de 3,6\% a 16\% (Pinto y Salazar 2002:123-124). Es necesario destacar la trascendental necesidad que la industria del cobre representaba para los capitales foráneos. En efecto, durante la primera mitad del siglo XX, con el desarrollo de las industrias automotriz y eléctrica, el cobre se constituiría en el metal clave para el desarrollo industrial (Machado 2013:68).

Si bien el proceso de irrupción del capital norteamericano no fue acogido de manera tácita, levantando resquemores de las nuevas corrientes desarrollistas de la CEPAL que consideraban este hecho como una hipoteca del patrimonio nacional, esta situación fue resuelta a favor de una minería estatal. Primero con la chilenización de la gran minería del cobre bajo el gobierno de Eduardo Frei Montalva, la que consistió, no en un posicionamiento contrario a las empresas extranjeras, sino más bien una asociación con el capital transnacional que permitiese velar por los intereses nacionales y aprovechar la tecnología y las potencialidades financieras de estas entidades (Pinto y Salazar 2002:127). Se procedió a suscribir convenios que derivaron en la adquisición por parte del Estado del $51 \%$ de la propiedad de la gran minería del cobre mediante la creación de la Corporación del Cobre (CODELCO). La Unidad Popular vino a profundizar este proceso mediante la nacionalización de la Gran Minería, volviéndose ley el 16 de julio de 1971. En términos generales, la nacionalización apelaba a que el control de riquezas básicas era una medida indispensable para garantizar la independencia económica y una plena soberanía.

Tanto el proceso de chilenización del cobre impulsado por Frei Montalva y posteriormente la nacionalización de la minería por Salvador Allende no alcanzaron a consolidarse, y las transformaciones estructurales impulsadas por la dictadura cívicomilitar reorientaron la actividad minera hacia la transnacionalización y privatización.

\section{Un nuevo marco jurídico-institucional ad hoc para la industria minera}

Como señalamos anteriormente, el rol del Estado lejos de perder protagonismo fue fundamental para la reproducción del capitalismo en su momento neoliberal. En concreto, desde 1973 hasta 1989 el Estado llevó a cabo ciertas reformas estructurales que cimentaron el campo propicio para la llegada de capitales extranjeros y la profundización de las actividades extractivas en general, y de la industria minera en particular (Agacino et al. 1998: 45). Dentro de estas identificamos: el DL 600 o Estatuto del Inversionista Extranjero; la Ley Orgánica Constitucional de Concesión Minera; el Código de Minería; y el Código de Aguas.

Desde 1989 en adelante la inversión extranjera directa pasó a representar montos muy significativos, pasando desde 974 millones de dólares en 1989, a 5.000 millones para 1997, demostrando las facilidades otorgadas al capital extranjero. Además, del total de inversión extranjera directa, el mayor porcentaje fue a parar a la industria minera. Desde 1974 hasta 1977 bordeó el 30\%; para inicios de la década de 1990 representaba el 60\%, y para 1994 llegó al 70\% (Moguillansky 1998:15).

A lo anterior se suma que desde 1987 se percibe una fuerte alza de inversión extranjera en la industria minera. Incluso más que lo invertido en CODELCO. Entre 1993 y 1997 se invierten en promedio 400 millones de dólares en CODELCO, mientras que en el mismo periodo la cifra invertida por los capitales extranjeros alcanza un promedio de 1.400 millones de dólares (Moguillansky 1998:12). La búsqueda de una salida pactada de la dictadura, sumado a la consolidación de un marco jurídico-institucional ad hoc al capital nacional y transnacional, y el ciclo 
de bonanza en los precios del cobre, podrían ser los factores que expliquen la estabilidad, confianza $\mathrm{y}$, por consiguiente, el despegue de las inversiones extranjeras en la industria minera.

Además del Estatuto de Inversión Extranjera, se impulsaron algunas reformas que a la postre fueron funcionales a las dinámicas de apropiación, mercantilización y degradación de la naturaleza. En 1981 se dicta un nuevo código de aguas que transformó profundamente la lógica del sistema de derechos de aguas del país: "fortaleció la propiedad privada, introdujo mecanismos e incentivos de mercado y limitó el poder regulatorio del Estado (Bauer 2002:15).

Al código de aguas se suman la Ley Orgánica Constitucional de Concesiones Mineras en 1982, y el Código de Minería en 1983, los que establecían:

El principio de no discriminación entre nacionales y extranjeros, la libertad de exploración (servidumbres incluidas), se introducía el concepto de "concesión plena" (que consagraba el derecho de propiedad a perpetuidad) y se establecía un criterio de "indemnización justa" en caso de expropiación "conforme al daño patrimonial efectivamente causado" (Folchi 2003:24).

En conjunto conformaron los cimientos legales que permitieron la irrupción de los capitales transnacionales, y por esta razón, la profundización de los proyectos con vocación extractivista. El sector pesquero, forestal, energético y por supuesto el minero, se vieron afianzados y con las condiciones necesarias para seguir expandiendo sus actividades.

Como consecuencia de lo expuesto anteriormente, creemos que el abordaje de la industria minera en general y de un conflicto en particular, debe partir de un análisis que supere los marcos cronológicos y geográficos acotados. La relación entre la vocación minera y el proceso de modernización e inserción del país en el desarrollo del capitalismo histórico; la irrupción de capitales extranjeros y la alta demanda del cobre a nivel mundial; la posibilidad de explotar nuevos yacimientos como consecuencia de los avances tecnológicos; la constitución de la industria minera como campo de disputa político-social, son elementos sin los cuales no podríamos explicar la instalación del Complejo Minero Los Pelambres en la cuenca del Choapa. El conflicto se expresa en un periodo determinado y de manera localizada, pero responde a procesos de larga duración y de carácter tanto nacional como global.

\section{Los Pelambres: de yacimiento a complejo minero}

Pero volviendo a nuestra pregunta inicial. ¿Cuáles fueron los factores histórico-ecológicos que permitieron la materialización del Complejo Minero Los Pelambres en la cuenca del río Choapa, más específicamente en la última década del siglo XX?

Para entender cómo y por qué fue posible la instalación del CMLP debemos volver hasta 1914, año en el que el ingeniero William Braden Burford explora y descubre este yacimiento ubicado en la actual provincia de Illapel, IV Región de Chile, el que debe su nombre a que, en plena primavera, las aguas de deshielo muy ácidas por el contacto de minerales pelaban las patas de los diversos animales que cruzaban las vertientes.

Un primer elemento, de carácter histórico, radica en la crisis de la minería en el norte chico a mediados del siglo XX y el sentimiento de postergación que tenían las diversas localidades con el Estado. Después de haber experimentado el auge cuprífero de las décadas de 1840 y 1860 , la provincia de Coquimbo en general desde el punto de vista de su estructura económica poseía una baja productividad y niveles de vida insatisfactorios. Además, como señala Ortega (2012), una inestabilidad económica, deterioro de los recursos agrícolas, emigraciones hacia otras regiones del país. En síntesis, existía una gran masa de población completamente marginados de la actividad económica y social, encontrándose sus niveles de vida entre los más bajos del país. Ante esta sensación de inseguridad e incertidumbre, el imaginario del desarrollo, el crecimiento económico y del empleo, despiertan expectativas y sueños respecto de un futuro más próspero y seguro (Composto y Navarro 2012:70).

En segundo lugar, debemos considerar el gran avance tecnológico de la industria minera. Pese a que desde un principio se tenía conocimiento del gran tonelaje que poseía, la baja ley de mineral -un promedio de $0,51 \%$ - hace que recién en 1969 , con la aparición y perfeccionamiento de nuevos procesos tecnológicos como la flotación y lixiviación, haga posible pensar su explotación. En ese contexto ENAMI comienza a definir el potencial exacto y ya en 1978 Anaconda Minerals adquiere los 
Tabla 1. Producción anual de cobre Minera Los Pelambres (en miles de toneladas métricas).

\begin{tabular}{rrrr}
\hline 1999 & 12,3 & 2006 & 335,2 \\
2000 & 308,8 & 2007 & 300,1 \\
2001 & 373,8 & 2008 & 351,2 \\
2002 & 335,5 & 2009 & 322,6 \\
2003 & 337,8 & 2010 & 398,0 \\
2004 & 362,6 & 2011 & 426,1 \\
2005 & 333,8 & 2012 & 417,7 \\
\hline
\end{tabular}

Fuente: Producción Minería. Comisión Chilena del Cobre.

derechos para su explotación. En 1985 Antofagasta Holding adquiere Anaconda Chile, por tanto, los derechos sobre Pelambres. Si bien ya en 1992 la mina comienza a funcionar, sus operaciones son a baja escala; $5 \mathrm{ktdp}$ (miles de toneladas métricas por día). El tercer elemento radica en la aparición de inversionistas extranjeros en un contexto, como vimos en las secciones anteriores, de promoción y apertura económica. 1997 es el año clave. Por una parte, ingresan en el directorio adquiriendo el $40 \%$ de las acciones un consorcio japonés conformado por Nippon Mining \& Metals, Mitsubishi Materials, Marubeni, Mitsubishi Corp. y Mitsui $\&$ Co. A lo anterior se suma la aprobación de un estudio de impacto ambiental y la construcción y puesta en marcha, en 1999, del Complejo Minero Los Pelambres (84 ktdp), año en el que terminan produciendo 12,3 miles de toneladas métricas (Tabla 1). El 2004 crece exponencialmente la capacidad de producción llegando a 362,6 miles de toneladas métricas. Para el 2011 alcanza las 426,1.

Este aumento sustantivo en la producción tiene que ver con el cuarto gran elemento que explica la viabilidad del CMLP; La demanda mundial y el precio del cobre en el contexto del boom minero. La lógica expansionista de los 80 , que ante el riesgo de una cercana devaluación, había que intensificar la explotación del recurso en el presente y obtener con ello la mayor renta posible (Folchi 2003: 46). Dicho proyecto no lo podía asumir el sector público, para ello era fundamental abrir la puerta a los consorcios extranjeros. Si analizamos el precio histórico del cobre desde 1999, año en que comienza a funcionar a gran escala el CMLP, hasta 2011, podemos ver una escalada exponencial (Tabla 2). En 1999 era de 71,380 centavos por libra, en 2005 ya alcanzaba los 167,087 centavos por libra. Y para el 2011 llegaba a su máximo histórico por sobre los 399,656 centavos por libra.
Tabla 2. Precio mundial de cobre (en centavos por libra) por año.

\begin{tabular}{lcll}
\hline 1999 & 71,38 & 2006 & 305,295 \\
2000 & 82,294 & 2007 & 323,246 \\
2001 & 71,566 & 2008 & 315,316 \\
2002 & 70,647 & 2009 & 234,217 \\
2003 & 80,734 & 2010 & 341,978 \\
2004 & 130,106 & 2011 & 399,656 \\
2005 & 167,087 & 2012 & 360,593 \\
\hline
\end{tabular}

Fuente: Información de la Minería. Sociedad Nacional de la Minería.

\section{Implicancias ambientales respecto de la cuenca del río Choapa}

Partimos nuestro recorrido a $3.200 \mathrm{msm}$, en los glaciares rocosos. Siguiendo el estudio de Azócar y Brenning (2010), son tres los elementos a destacar. Primero, la importancia de los glaciares rocosos en regiones áridas y semiáridas es fundamental, al constituir reservorios de aguas, y más aún, durante los meses secos. Segundo, se estima que hasta el 2006, debido a la construcción de botaderos de material estéril y de caminos, además de las tronaduras y explosiones, el total de hielo afectado equivale en agua líquida entre 1.900 y 2.800 millones de metros cúbicos. Tercero, la degradación de los glaciares no solo implica la pérdida de agua, sino también varias consecuencias para las localidades cercanas a las cuencas hidrográficas. Por una parte, los procesos geoquímicos producen drenajes ácidos con alto contenido de metales pesados, es decir, directa contaminación de las aguas. Además, la construcción de depósitos de roca estéril sobre los glaciares altera las condiciones térmicas, aumentando el riesgo de deslizamientos.

Otra implicancia ambiental radica en la construcción de tranques de relaves, los que tienen por objetivo el depósito del material sobrante del proceso de extracción del mineral. Tomaremos el ejemplo del tranque de relaves El Mauro, ubicado en la cabecera del estero Pupío, situado a $10 \mathrm{~km}$ del pueblo de Caimanes y $50 \mathrm{~km}$ al noroeste del balneario de Los Vilos. Primero es necesario señalar que la Región de Coquimbo no se caracteriza por poseer grandes provisiones hídricas. Las características hídricas del valle:

están dadas por prolongados períodos de sequía (7 de 10 años con 300 mm. Promedio 
de precipitaciones anuales), los que son superados con gran dificultad, gracias a infiltraciones y acuíferos subterráneos existentes en el área de El Mauro. En dicha zona el agua subterránea tiene su origen en vertientes y afloramientos que contribuyen a la formación de vegas y bofedales, además de constituir un aporte vital a caudales de agua superficial y subterránea con uso para riego y consumo humano (OLCA 2004).

Así, la degradación irremediable del sistema hidrológico de la cuenca del río Choapa, uno de los principales impactos ambientales que tiene la presencia del tranque de relaves, toma aún más relevancia debido a las características geográficas y climáticas de la zona. Ahora bien, cuando decimos que existe una degradación irremediable del sistema hidrológico, no solo nos referimos al agotamiento de las reservas de agua, sino también a su contaminación por metales pesados.

Mediante un estudio realizado por el Colegio Médico (Tchernitchin 2012) se demostró en primer lugar, que el tranque de relaves el mauro contamino las reservas de agua potable del estero Pupío y el agua potable del pueblo de Caimanes, con una serie de metales pesados que se registraron por encima de la norma chilena. Entre ellos el manganeso, hierro, mercurio, níquel y molibdeno. En segundo lugar, y como consecuencia de lo anterior, se alertaba sobre diversos efectos que tendría la exposición a cada uno de los metales. Por ejemplo, la exposición prolongada en el caso del manganeso puede provocar entre otras cosas infertilidad, disfunción eréctil. Además de que su exposición prenatal causaría daños neurológicos irreparables y diversas malformaciones fetales. La exposición prolongada de mercurio puede producir daño irreversible en el sistema nervioso central, principalmente cerebro, riñones, y el feto. Por otra parte, el níquel induce el desarrollo de cáncer pulmonar y cáncer nasal. La contaminación de las aguas, además de afectar directamente la salud de los pobladores, amenazaba la continuidad de las actividades económicas y de sustento -por ejemplo, la agricultura- para los habitantes y familias del valle del Pupío. En suma. la instalación de los tranques de relaves se constituyen como una amenaza, no solo para los ecosistemas (cuencas hidrográficas, napas subterráneas, flora y fauna), sino también para los propios pobladores de las distintas localidades del sector.
Otro nudo conflictivo se generó a raíz de la instalación del terminal marítimo en el puerto de Los Vilos. Dichas instalaciones -encargadas del proceso de embarque del concentrado- provocarían daño ambiental y serian perjudiciales para el turismo y entorpecería las labores de pesca. Lo anterior se fundamentaba en los potenciales riesgos que implicaba el manejo de 743.000 toneladas anuales de concentrado de cobre y 8.500 de molibdeno, en un medio de tanta fragilidad como la Bahía de Conchalí, donde ocurre una compleja configuración de fondo marino, corrientes y sistema de vientos. (OLCA 2004:3-4). Lo anterior podría ocasionar eventos contaminantes en suelos, napas subterráneas, y por consecuencia, en el ecosistema marino de la bahía, que quedaría expuesto a los efectos de metales pesados.

Cuando al comenzar nuestro trabajo señalábamos la importancia de analizar los procesos de apropiación de la naturaleza desde la perspectiva del metabolismo social, nos referíamos concretamente a las implicancias ambientales recién expuestas. La contaminación y degradación de la naturaleza significa a su vez la contaminación y degradación de quienes viven con y de ella. En síntesis, la instalación del Complejo Minero Los Pelambres implica un proceso de destrucción de la naturaleza humana y extrahumana.

\section{Conclusiones y proyecciones de la investigación}

El presente artículo se propuso dar cuenta de los elementos histórico-ecológicos que permitieron la materialización del CMLP y sus implicancias ambientales. Así entonces, no podemos comprender la instalación de un complejo minero y sus consecuencias ambientales y sociales, en una esfera aislada de los procesos político-sociales que lo impulsaron. En efecto, la configuración de un marco jurídico funcional a la industria minera, la posibilidad del ingreso de capitales extranjeros, los avances tecnológicos de la industria minera y las implicancias ambientales, en su conjunto, se presentan como la materialización de una forma específica de producción de naturaleza, y una consecuente reconfiguración metabólica de la cuenca del río Choapa.

Con el interés de darle proyección a la presente investigación, creemos necesario abordar al menos dos elementos problemáticos. En primer lugar, el 
conflicto desatado por la instalación del CMLP, particularmente las estrategias de inserción y legitimación de Minera Los Pelambres en la provincia del Choapa y la compleja conformación y acción de los actores que se tensionan en el conflicto. Por otra parte, creemos necesario comprender cuáles son los soportes histórico-culturales de cada una de las localidades que dieron forma a las diversas respuestas frente al conflicto desatado por el Complejo Minero Los Pelambres en la cuenca del Choapa.

\section{Agradecimientos}

Agradezco al centro de estudios PROCESO por la retroalimentación de elementos claves que sustentaron la presente investigación.

\section{Referencias Citadas}

Agacino, R.; González, C. y Rojas, J.

1998 Capital Transnacional y trabajo. El Desarrollo Minero en Chile. LOM, Santiago.

Bauer, C.

2002 Contra la Corriente. Privatización, Mercados de agua y el Estado en Chile. LOM, Santiago.

Brenning, A. y Azócar Guillermo

2010 "Minería y glaciares rocosos: impactos ambientales, antecedentes políticos y legales, y perspectivas futuras". Revista de Geografía Norte Grande No 47:143-158.

Camus, P. y Hajek, E.

1998 Historia Ambiental de Chile. Andros Impresores, Santiago.

Cepeda, C.

2016 "Extractivismo y luchas sociales en torno al enclave minero del Norte de Chile: el caso de Calama". Actuel Marx intervenciones: El sociometabolismo del Capital y la depredación de la Vida. Debates sobre el extractivismo. $\mathrm{N}^{\circ}$ 20:15-42, Santiago.

Composto, C. y Navarro, M.

2012 "Estados, transnacionales extractivas y comunidades movilizadas: dominación y resistencias en torno de la minería a gran escala en América Latina". Theomai No 25:58-78.

Folchi, M.

2003 "La insustentabilidad del boom minero chileno: política y medio ambiente, 1983-2003”. Ecología Política $\mathrm{N}^{\circ} 26: 23-49$.

Gárate, M.

2012 La Revolución Capitalista de Chile (1973-2003). Ediciones Alberto Hurtado, Santiago.

Gudynas, E.

2015 Extractivismos. Ecología, economía y política de un modo de entender el desarrollo y la Naturaleza. CEDIB, Cochabamba.

Harvey, D.

2003 El nuevo Imperialismo. Akal, Madrid.

Harvey, D.

2007 Breve historia del neoliberalismo. Akal, Madrid.

Machado, $\mathrm{H}$.

2016 "Sobre la Naturaleza realmente existente, la entidad 'América' y los orígenes del Capitaloceno. Dilemas y desafíos de especie". Actuel Marx: El sociometabolismo del Capital y la depredación de la Vida. Debates sobre el extractivismo. $\mathrm{N}^{\circ}$ 20:205-230, Santiago.

Marx, K.

1980 Manuscritos economía y filosofía. Alianza Editorial, Madrid.
Moguillansky, Graciela

1998 "Las inversiones en el sector Minero 1980-2000". Reformas economicas $\mathrm{N}^{\circ} 3$.

Moore, J.

2013 "El auge de la ecología-mundo capitalista. Las fronteras mercantiles en el auge y decadencia de la apropiación máxima". Laberinto $\mathrm{N}^{\circ}$ 38:10-26.

Moore, J.

2014 "De objeto a oikeios: la construcción del ambiente en la ecología-mundo capitalista". Sociedad y Cultura $\mathrm{N}^{\circ} 2$ : 87-107.

Observatorio Latinoamericano de Conflictos Ambientales 2004 Informe Técnico final: estrategias de gestión de las diferentes etapas del conflicto compañía Minera Los Pelambres vs pescadores de los Vilos y agricultores de los Valles del Choapa y Pupío en la cuarta región de Chile. http://olca.cl/ oca//chile/region04/mlp/olca_mlp/informes/informes_pdf/ tecnico_final.pdf (12 agosto 2017).

O'Connor, J.

2001 Causas naturales. Ensayos de marxismo ecológico. Siglo XXI, México.

Ortega, L.

2012 "La crisis de la minería del cobre en el Norte tradicional (Norte Chico, Chile) en la primera mitad del siglo XX y la decadencia de la Región de Coquimbo". Tiempo histórico No 4: 43-66.

Ortega, L. y Pinto, P.

1990 Expansión Minera y Desarrollo Industrial: un caso de Crecimiento asociado. Departamento de historia Universidad de Santiago de Chile, Santiago.

Pederson, L.

1966 La Industria Minera del norte chico, Chile. Ril editores, Santiago.

Salazar, G. y Pinto, J.

2002 Historia Contemporánea de Chile III. La Economía: Mercados, Empresario y Trabajadores. LOM, Santiago.

Seoane, J.

2012 "Neoliberalismo y ofensiva extractivista. Actualidad de la acumulación por despojo, desafíos de nuestra América". Theomai 26:5-32.

Tchernitchin, A.

2012 "Efectos sobre la salud y el medio ambiente en las actividades mineras en Chile. Contaminación del estero Pupío y agua potable del pueblo de Caimanes: ¿Se origina desde el tranque de relaves mineros El Mauro?". Cuadernos Medico Sociales No 4:199-214. 
Vergara, A.

2011 “"Cuando el río suena, piedras trae': relaves de cobre en la bahía de Chañaral 1938-1990”. Cuadernos de Historia $\mathrm{N}^{\circ} 35: 135-151$.
Yáñez, N. y Molina, R.

2008 La gran Minería y los Derechos Indígenas en el norte de Chile. LOM, Santiago. 